\title{
Propiedad intelectual y libre acceso a la información: aporía actual del conocimiento
}

\author{
Francisco Guevara QuiEL \\ Escuela de Lenguas Modernas \\ Universidad de Costa Rica
}

\begin{abstract}
Resumen
Este artículo se enfoca en la resolución C-117/13 de la Corte de Justicia Europea sobre la flexibilización de los derechos de autor para fines científicos y académicos. Abordamos también el problema del libre acceso a la información y aportamos ciertos elementos de reflexión en relación con las sociedades de la información, nuevo paradigma del conocimiento del siglo XXI.
\end{abstract}

Palabras claves: derechos de autor, biblioteca, bibliotecología, libre acceso, sociedad de la información, Corte de Justicia Europea, CJE, OMPI

\section{Abstract}

This article focuses on resolution C-117/13 of the Court of Justice of the European Union regarding the flexibility of copyright for scientific and academic purposes. We also address the issue of Open Access information and provide some insights about Information Societies, new paradigm of knowledge of the $21^{\text {st }}$ century.

Key words: copyright, library, library science, open access, information societies, Court of Justice of the European Union, CJEU, OMPI

U no de los grandes desafíos que enfrenta la biblioteca moderna, como es sabido, es cuestionar constantemente sus fundamentos para llevar a cabo los cometidos a los que está llamada, pero también prever, en la medida de lo posible, cam- bios oportunos a futuro y proyectarse más allá de las coyunturas actuales. Ello implica una revisión ontológica y epistemológica dinámica en la medida en que debe ajustarse a las demandas de información que los nuevos tiempos requieren. Sin embrago, esto supone no 
solo tratar de enfrentar ciertas aporías científicas e incursionar en procesos investigativos a lo interno, sino también difundir a lo externo el saber y el conocimiento actualizados adquiridos por la vía oportuna y adecuada, para con ello ofrecer un servicio con información relevante, pertinente, actual y de calidad a los usuarios, investigadores especializados, estudiosos o simples curiosos interesados en el quehacer epistemológico.

Esto podría, sin embargo, enfrentar algunos escollos considerables, en particular en materia de derechos de autor, cuando se trata de difundir información cuya naturaleza ostenta un carácter privativo. Se trata de un debate álgido que remonta ya a menos de dos décadas aproximadamente en un contexto de litigio en Europa, llevado a cabo en particular por la Universidad Técnica de Darmstadt y la casa de edición Eugen Ulmer KG, en Alemania, la cual reclama ante la Corte de Justicia Europea la posibilidad de divulgar resultados de investigaciones científicas en formato numérico dentro de sus instalaciones sin que sea necesario el acuerdo de los titulares de los derechos de autor ${ }^{1}$.

Dejando de lado por el momento este caso que motiva el presente trabajo y del que nos ocuparemos oportunamente, cabría plantearse ciertas interrogantes que revelan necesariamente un conflicto de intereses en la era de las sociedades de la información. ¿Los derechos de autor deben prevalecer como jerárquicamente superiores en tanto bien jurídico tutelado por el ordenamiento jurídico de un Estado o por el contrario, debe privilegiarse el acceso y el derecho al conocimiento por parte del público de manera gratuita? ¿La investigación científica, sobre todo la realizada en ámbitos universitarios, tiene vocación para ser difundida ampliamente ante el público o debe existir cierto deber de reserva en pro de los derechos de autoría e intelectualidad para el manejo óptimo de información importante y de calidad? ¿Hoy, qué papel debe jugar la biblioteca en su labor de difusión del conocimiento y cuáles son sus límites? ¿Cuáles son los retos a los que se enfrenta el conocimiento en su adquisición, difusión y aplicación concretas? ¿Cómo debe posicionarse la biblioteca ante estos desafíos?

En este ensayo no se pretende dar una respuesta definitiva a los cuestionamientos planteados, los cuales de todos modos solo pueden ser contemplados y evaluados adecuadamente dentro de una perspectiva histórica y evolutiva; sin embargo, se tratará de exponer algunos argumentos que puedan permitir una lectura amplia en cuanto a la problemática de los derechos de autor y la divulgación de la información científica, al tomar en cuenta no solo los esfuerzos significativos de los distintos instrumentos legislativos creados para su regulación, sino también el camino ya trazado por decisiones de justicia con carácter vinculante por parte de altas instancias jurisdiccionales europeas (lo que no impide que en nuestro contexto nacional hagan falta pronunciamientos y debates relativos al tema), quienes al fin y al cabo interpretan la ley y la hacen ejecutar, marcando así la pauta por seguir. Finalmente serán propuestas algunas soluciones o alternativas.

\section{Derechos de autor y propiedad intelectual}

Dado que en materia de derechos de autor y propiedad intelectual la 
legislación y la doctrina son abundantes, en el ámbito nacional y supranacional, así como organizacional y mundial, a raíz de lo cual se han hecho correr torrentes de tinta por parte de especialistas, de defensores y detractores, sería ocioso aquí tratar de abordar y desplegar todo el arsenal estructural de argumentos que han surgido desde que se trata este tema en relación con las sociedades de la información y su movimiento de libre acceso, discusiones que remontan ya a varias décadas y que tienen un fuerte impulso en los Estados Unidos y en Europa $^{2}$. De este modo, parece pertinente rescatar los principios básicos generales sobre los que se fundan estas nociones. Sin embargo, en términos pragmáticos y desde el punto de vista normativo, cabe destacar que en última instancia es la legislación la que va estableciendo las pautas regulativas en la materia paralelamente con las decisiones de justicia. Estas crean jurisprudencia interpretativa vinculante a partir del momento en que altas instancias judiciales dirimen los conflictos de intereses y revierten con carácter de firme sus interpretaciones del espíritu de la ley, sobre el cual reposan justamente los principios generales de los bienes por ella protegidos a los que hacemos alusión. En este sentido, algunos aspectos conceptuales se hacen necesarios.

¿A qué se le llama derecho de autor? Puede decirse que se trata de una prerrogativa atribuida al autor de una creación del espíritu y que comporta un derecho moral y patrimonial ${ }^{3}$. Es así como lo reconocen muchas de las legislaciones estatales en sus propios ordenamientos jurídicos y ciertos tratados internacionales, como el Tratado de la
$O M P I^{4}$ sobre el derecho de autor, adoptado en Ginebra el 20 de diciembre de $1996^{5}$. Este surge, entre otros motivos, en reconocimiento a la evolución y convergencia de las técnicas de la información y de la comunicación cuya incidencia es considerable en la creación y la utilización de las obras literarias y artísticas, como reza el preámbulo. También recalca la importancia fundamental que tiene la protección del título de derecho de autor para alentar este tipo de creaciones, de manera que se pueda al mismo tiempo establecer un equilibrio entre tales derechos y el interés público general. Constituye un apecto medular sobre el que se ha colegido el interés por divulgar el conocimiento resultante de investigaciones científicas. Las diferentes legislaciones nacionales, extranjeras y supranacionales relevan los principios contenidos en ese dispositivo en concordancia bastante homogénea con ellos.

\section{A. Normativa nacional y extrajera}

En el nivel estatal, en el caso particular de Costa Rica, la legislación, de manera más o menos precisa, trata de definir los objetos sometidos a protección de la autoría. Así, la Ley de derecho de autor y derechos conexos establece de forma amplia que: "Por "obras literarias y artísticas", en adelante "obras", deben entenderse todas las producciones en los campos literario, científico y artístico, cualquiera que sea la forma de expresión"6. Esta ley se complementa con la ley de Procedimientos de observancia de los derechos de propiedad intelectual (que se hace eco directo del Tratado de la OMPI) y sanciona como delito, en la sección 
III del capítulo V (artículo 51 y ss.), el empleo de medios técnicos para la representación, reproducción, edición y difusión de las obras del autor sin autorización a partir del momento en que son puestas al alcance del público. En el inciso d del art. 54 se lee textualmente: "No será punible la reproducción, sin fines de lucro, de obras literarias o artísticas, o fonogramas en la medida requerida para cumplir fines ilustrativos para la enseñanza, con tal de que esa reproducción sea conforme a los usos debidos y se mencione la fuente y el nombre del autor, si este nombre figura en la fuente". Empero, la ley no deja claramente establecido lo relativo a investigaciones científicas, con lo cual el término "obras" adquiere un sentido muy amplio y queda al juicio del administrador de justicia la interpretación del espíritu de la ley de acuerdo con los principios de la sana crítica racional, la doctrina y la jurisprudencia. A pesar de ello, el legislador no dejó de contemplar específicamente la labor de difusión que tiene la biblioteca, cuando señala en el párrafo 2 del art. 62 que: "No se impondrán sanciones penales en las conductas indicadas, cuando estas sean realizadas por funcionarios de bibliotecas, archivos, instituciones educativas $u$ organismos públicos de radiodifusión no comerciales sin fines de lucro, en el ejercicio de sus funciones", con lo cual se da un paso significativo con incidencia en la difusión del conocimiento. En varios artículos de la ley se refleja de manera bastante precisa la preocupación del legislador en no prever sanciones para conductas delictivas tipificadas en caso de que se trate de funcionarios de bibliotecas, archivos o instituciones educativas sin fines de lucro ${ }^{7}$.
Cabe señalar al respecto que la ley costarricense, a pesar de sus carencias y a veces falta de eficacidad, ofrece sin embargo un instrumental jurídico fundamental para garantizar la protección del derecho de autor y divulgación del conocimiento.

Por otra parte, a título de ejemplo de normativa extrajera, la ley francesa en particular, sujeta a las directivas del Parlamento y de la Corte de Justicia de la Unión Europea, prevé un sistema de depósito legal destinado a asegurar la preservación del patrimonio cultural y la información de ciertas autoridades administrativas, dentro de las que se encuentran las bibliotecas. Se trata de todo tipo de obra, sea cual fuere la técnica de producción, de difusión o edición, desde el momento en que es puesta a disposición del público, lo cual también le confiere derechos a esas instituciones ${ }^{8}$.

La ley francesa, en concordancia con los tratados comunitarios e internacionales, ha previsto específicamente que el derecho de representación "consiste en la comunicación de la obra al público mediante cualquier procedimiento", al tiempo que prevé excepciones a esos derechos en el marco de la sociedad de la información, como los siguientes:

- "La representación o la reproducción de extractos de obras, bajo reserva de obras concebidas con fines pedagógicos, partituras de música y obras realizadas para una edición digital del escrito, con fines exclusivos de ilustración en el marco de la enseñanza y la investigación [si] el público al que está puesta a disposición es mayoritariamente constituido de alumnos, estudiantes, educadores o investigadores directamente concernidos". 
- "La reproducción y la representación por parte de personas morales y por establecimientos abiertos al público, tales como bibliotecas, archivos, centros de documentación y espacios culturales multimedia, con miras a una consulta estrictamente personal de la obra".

- "En ningún caso estos establecimientos pueden perseguir fines de lucro con la representación de una obra"10.

\section{B. Normativa supranacional}

Ya hemos evocado el Tratado de la OMPI, el cual es un instrumento jurídico de base importantísimo en el concierto de las naciones para la regulación de los derechos de autor de caracter mundial. Su articulado es bastante preciso en cuanto a sus alcances y prevé una serie de situaciones interesantes al tener en cuenta la implementación de nuevas tecnologías para efectos de reproducción y acceso a la información. Así por ejemplo, queda entendido que la protección del derecho de autor se extiende a manifestaciones o expresiones concretas de creación, es decir, perceptibles por los sentidos, pero no a las ideas, procedimientos, métodos de operación o conceptos matemáticos en sí (art. 1), que son de curso libre. Se aclara que el derecho de reproducción de una obra protegida (sobre todo su almacenamiento en un soporte electrónico) y sus excepciones se aplican plenamente en el entorno digital, en particular a las obras en este formato. La protección se aplica también a los programas de computación (art. 3) y a las compilaciones de datos (bases de datos) o de otros materiales que constituyan creación intelectual (art. 5).
Del mismo modo, se establece que los autores tienen el derecho exclusivo de autorizar la puesta a disposición del público del original y de los ejemplares de sus obras mediante venta o transferencia de la propiedad, sin detrimento de las condiciones que hayan fijado las partes contratantes (art. 6). Resulta muy interesante que el tratado prevea al mismo tiempo que los autores gocen del derecho exclusivo de autorizar cualquier comunicación al público de sus obras, lo que incluye el lugar y el momento en que este pueda acceder a ellas según lo acuerden las partes, aspecto que podría revertir un carácter litigioso, como lo veremos más adelante (art. 8). Sin embargo, cada Estado podrá limitar excepcionalmente los derechos de autor en casos especiales que no atenten contra la explotación normal de la obra siempre y cuando no se cause un perjuicio al autor (art. 10), punto que manifiestamente queda sujeto a interpretación y podría generar un debate álgido en cuanto a sus alcances (cuando no un diálogo de sordos, como en el caso de la legislación de Costa Rica muy sometida a derogaciones y reformas de fondo), sobre todo al tratarse de asuntos relacionados con medidas tecnológicas que podrían afectar los intereses legítimos de los autores, pues los Estados quedan sujetos a dar medidas de protección jurídica (art. 11). En fin, los suscribientes del tratado quedan obligados a crear sanciones contra la distribución, importe para distribución, emisión y comunicación al público de los ejemplares de las obras sin autorización previa del autor, punto a todas luces igualmente controversial (art. 12, ii).

Finalmente, en el caso europeo, podemos invocar la Directiva 2001/29/ 
CE del Parlamento Europeo y del Consejo del 22 de mayo del 2001 sobre la armonización de ciertos aspectos del derecho de autor y de los derechos afines en la sociedad de información ${ }^{11}$. La directiva es vinculante para todos los Estados miembros de la Unión y traduce una verdadera preocupación por la protección de los derechos de autor y afines, al mismo tiempo que instaura un sistema eficaz que garantiza que la competencia dentro del mercado no sea falseada, armonizando para ello los criterios legislativos entre los miembros para así evitar cacofonías interpretativas. El articulado es abundante y detallado, y prevé un sinnúmero de situaciones que podrían presentarse, dando así prueba de visión y perspectiva de avanzada.

La directiva considera en su párrafo 5 que si "la protección de la propiedad intelectual no requiere que se definan nuevos conceptos, las actuales normativas en materia de derechos de autor [...] deben adaptarse y complementarse para responder adecuadamente a las realidades económicas tales como las nuevas formas de explotación”, todo esto con miras a evitar incoherencias e inseguridad jurídica a medida que aumentan y se desarrollan las sociedades de la información. La idea es preservar la propiedad intelectual e incentivar la creatividad, así como compensar adecuadamente a los autores por el uso de la obra, previendo al mismo tiempo excepciones o limitaciones a favor del interés público para fines educativos y docentes (párrafo 14). Por otra parte, se establecen limitaciones y excepciones al derecho de autor y afines cuando se persiga "una finalidad educativa o científica, en beneficio de organismos públicos, tales como bibliotecas o ar- chivos, con fines de información periodística”, etc. (párr. 34, y art. 5, párr. 2, inciso c), toda vez que haya una compensación equitativa que recompense el uso que se le dé a la información obtenida (párr. 35). Dichas excepciones deben limitarse, sin embargo, a una serie de casos específicos, como en el caso del art. 5, párr. 3, inciso n: "cuando el uso consista en la comunicación a personas concretas del público o la puesta a disposición, a efectos de investigación o de estudio personal, a través de terminales especializados instalados en los locales de los establecimientos mencionados en la letra c del apartado 2 , de obras y prestaciones que figuran en sus colecciones y que no son objeto de condiciones de adquisición o de licencia".

Como puede notarse, la coherencia entre estos dos instrumentos jurídicos es notoria. Sin embargo, no tendrían efectos concretos si no fueran interpretados en instancia judicial, como lo veremos enseguida.

\section{Una decisión de justicia con ca- rácter vinculante}

Es en cuanto al alcance de esta norma transnacional, en su art. 5, párr. 2, que la Corte de Justicia Europea dictó recientemente una sentencia con carácter vinculante para todos los miembros de la Comunidad Europea ${ }^{12}$ (el 11 de setiembre de 2014) en donde se deja por sentado que los autores tienen el derecho exclusivo de autorizar o de prohibir la reproducción y la comunicación al público de sus obras, y que sin embargo ella prevé que los Estados establezcan ciertas excepciones o limitaciones a ese derecho, facultad que existe en el caso preciso de las bibliotecas 
accesibles al público, las cuales con fines de investigación y estudios privados, pueden poner obras de su colección a disposición de los usuarios por medio de terminales especializados.

$\mathrm{El} \mathrm{caso}{ }^{13}$ surge en Alemania en enero de 2009, en un litigio que opone a la Universidad Técnica de Darmstadt con la editorial Eugen Ulmer KG. Esta última había propuesto a la Universidad que comprara sus libros en formato digital. La Universidad rehusó la propuesta y digitalizó los libros del editor sin su autorización y los puso a disposición de sus estudiantes en terminales de lectura al estimar que una oferta comercial sobre los mismos contenidos en formato digital no impedía la puesta en aplicación de la excepción. Así las cosas, el editor ataca en justicia a la Universidad. En marzo de 2011, la corte regional de Frankfort dictaminó que en este caso no se requería un acuerdo previo sobre los derechos digitales pues la legislación alemana prevé la excepción para las bibliotecas y la investigación, con lo que la Corte también rehusó la solicitud de la casa editorial de que se prohibiera la digitalización de sus libros por parte de la Universidad. Empero, la alta instancia judicial alemana le daba razón a la Eugen Ulmer KG en cuanto a que la biblioteca no estaba autorizada a permitir a los lectores copiar los libros digitalizados en dispositivos de almacenamiento como las llaves USB, ni de imprimirlos a partir de los terminales de lectura. La Universidad apela la decisión ante la Corte Federal de Justicia alemana, pero esta difiere su decisión en marzo de 2013 para elevar la consulta ante la Corte de Justicia Europea de manera que dirima el litigio y establezca claramente el alcance de las facultades que se arrogó Alemania.
En estas circunstancias, el 11 de setiembre de 2014, la Corte de Justicia de la Unión Europea publica una sentencia fundamental que marca jurisprudencia y cuyo dictamen:

- Primeramente, confirma que la biblioteca puede prevalerse de la excepción prevista en la ley con miras al interés público ligado a la promoción de las investigaciones y estudios privados y poner estos a disposición en terminales especializados, y también la faculta para digitalizarlas sin que medie necesariamente un contrato de licencia del propietario de los bienes.

- En segundo lugar, considera sin embargo que la biblioteca no puede permitir a los particulares imprimir las obras en papel ni almacenarlas en llaves USB a partir de esos terminales.

- Y en tercer lugar, agrega que los Estados miembros pueden prever excepciones para que los usuarios de la biblioteca puedan imprimir las obras y almacenarlas en llaves USB a partir de terminales especializados toda vez que medie una compensación equitativa revertida a los titulares de los derechos.

La Corte constata que esta excepción de puesta a disposición al público podría quedar vaciada de su substancia si las bibliotecas en cuestión no tuvieran un derecho accesorio a la digitalización, visto como un acto de reproducción específico. Es esta condición de especificidad la que enmarca esta excepción ya que los establecimientos no disponen del derecho de digitalizar la totalidad de su colección.

El impacto de esta decisión deberá sin duda ser considerable en lo sucesivo 
y modificará ciertamente la manera en que los servicios a los usuarios serán dispensados en la biblioteca, coligiéndose también que necesariamente las casas editoriales estarán a partir de ahora más atentas a la manera en que promocionarán las obras publicadas, no solo en Alemania sino en toda Europa, lo que tendrá igualmente repercusiones de nivel mundial. En este sentido, el abogado general que rinde las conclusiones, M. Niilo Jääskinen, recuerda que actualmente la digitalización de obras en manos de bibliotecas también ha constituido un objeto de litigio en el marco del proyecto Google Book Search, el cual se ventiló ante la Corte Distrital de Nueva York, en los Estados Unidos ${ }^{14}$, y que va aproximadamente en el mismo sentido en que se pronunció la Corte Europea. El panorama sobre la difusión y divulgación del conocimiento está ahora abierto, sobre todo en el marco de las sociedades de la información y gracias al impulso de los movimientos de libre acceso al conocimiento; sin embargo, habrá que observar la manera en la que los paradigmas se irán reorganizando y el impacto concreto que estas medidas tendrán en la sociedad sucesivamente.

\section{Libre acceso al conocimiento}

\section{A. Consideraciones generales}

En el marco de las sociedades de la información se tiene claro como presupuesto el hecho de que todos debemos estar debidamente informados, que la sociedad está llamada a operar cambios significativos para el bienestar general y mejorar la calidad de vida, lo que implica difundir ampliamente el conocimiento de manera que el mayor número de personas se beneficie. Si bien esto parece utópico, no deja de tener interés el hecho de que constituye un aliciente para generar propuestas y conocimiento que pueden circular por los medios adaptados a tales fines, en particular por la red Internet. En términos menos ambiciosos y más realistas, se trata de poner a disposición del público ciertas informaciones resultantes de investigaciones científicas serias orientadas al desarrollo social, y que se puedan consultar, utilizar y compartir.

Del mismo modo, el evidente progreso tecnológico al que asistimos hoy hace más accesible la información, por lo que es necesario adaptar los derechos de autor a los avances en tecnología, teniendo en cuenta los debates sobre la difusión de conocimientos en el área de la investigación, la ciencia y la enseñanza. En términos absolutos, la gran problemática consiste en plantear la conveniencia de ampliar, y hasta dónde, las excepciones y limitaciones a los derechos de autor y afines en la era de la difusión digital. En primera instancia, pareciera interesante que ciertos canales deben habilitarse cuando se trata de la digitalización de obras, la divulgación de obras huérfanas, el acceso a estas por parte de personas discapacitadas o habitantes de zonas geográficas alejadas, y también la previsión de medidas de protección para los creadores de contenidos de Internet toda vez que sus esfuerzos contribuyan al desarrollo.

Los esfuerzos de los movimientos de libre acceso a la información plantean excepciones en beneficio de archivos, bibliotecas, centros de investigación y de enseñanza. Estos abogan por una digitalización masiva de sus colecciones para conservar sus archivos y 
difundirlos en línea para lo cual se solicita más flexibilidad para tales fines, de manera que se beneficie el conjunto de la población y sobre todo aquellos con difícil acceso a la información, sea por razones de minusvalía o distancia. Las casas de edición, por su parte, se preocupan por la defensa de los derechos de autor y por la fragilidad de sus fuentes de ingresos, arguyendo que actualmente más del $90 \%$ de sus publicaciones ya figuran en línea y que invierten también en nuevos modelos de entrega electrónica. Por otra parte, esta situación plantea cuestiones relativas a la concesión de licencias para mejorar el acceso a las obras con fines educativos o de investigación, el aprendizaje a distancia y la consulta a domicilio con fines de estudio. Finalmente, en lo que concierne a los creadores de contenidos en el marco de las nuevas tecnologías, los usuarios deberían poder beneficiarse de un régimen de excepciones.

En esta reflexión deben intervenir las partes involucradas, a saber: bibliotecas, archivos y museos, editores, universidades, sociedades de gestión colectiva y agencias de concesión de licencias, confederaciones industriales y comerciales, representantes de personas con discapacidad, Estados signatarios de convenios y tratados internacionales, y toda otra parte concernida directamente. Nos interesa en particular el primero de los interventores mencionados: las bibliotecas.

\section{B. La biblioteca}

No cabe duda del interés público que tiene la biblioteca. Su posicionamiento en el debate releva de una ló- gica del servicio público con fines no comerciales y de facilitadora del conocimiento al hacerlo eficaz y accesible al mayor número de personas. El marco jurídico actual le impide digitalizar la totalidad de sus colecciones. Juega, sin embargo, un papel fundamental en la conservación y gestión a largo plazo de la herencia cultural de la sociedad, visión que no convence totalmente a los detentores de los derechos de autor que arguyen no oponerse a la misión de la biblioteca sin que la disposición de su material en línea se confunda con acceso gratuito. Es este carácter del acceso al conocimiento lo que se encuentra en el ojo del huracán y en el que se funda una aporía de la modernidad que, insoslayablemente, va a cambiar el curso de las relaciones humanas en el futuro próximo: ¿estaremos frente a una sociedad de libre intercambio o a la tradicional forma de economía de prestación de bienes y servicios remunerados?

La biblioteca aboga, igualmente, por el hecho de que en la actualidad el acceso a la información ha dejado de estar restringido a un espacio físico gracias a las nuevas tecnologías que han permitido la consulta de obras a domicilio, sobre todo porque la investigación y la enseñanza han adquirido un carácter internacional, virtual y movible. Toda limitación a estas situaciones iría en contra de la realidad de la vida moderna. En este sentido, es totalmente válido el hecho de definir claramente el término "obra" en sus alcances, ya que podríamos estar hablando de obras literarias (como novelas, piezas de teatro, etc.) de las cuales en principio vive un autor, y obras científicas o académicas de las que por regla general no vive el investigador y que más bien tienden a promover la reflexión y el conocimiento, 
en cuyo caso, al tratarse de trabajos financiados con fondos públicos y por ser fundados en trabajos de investigación precedentes, estos deberían ponerse a disposición de la comunidad científica y del público en general.

¿Cuál sería entonces el sistema por adoptar? Los defensores del Open Access, movimiento fuertemente arraigado en los Estados Unidos y muy activo que se ha extendido a todo el mundo ${ }^{15}$, se plantean cómo remplazar el sistema actual.

Pareciera importante crear un equilibrio de fuerzas, cuando no un cambio en sentido contrario, donde, gracias a una superplataforma de datos, se puedan incorporar los resultados de investigaciones científicas. Así, los publishers no serían propietarios de los artículos sino un comité editorial que rechace y apruebe las propuestas, y los publishers no serían más que unos proveedores de servicios que contribuirían a enriquecer la plataforma. La idea es crear competencia entre estos, algo a lo que no están acostumbrados, con la consecuente baja en los costos. Esta dinámica se justifica en la medida en que las investigaciones reposan en gran medida sobre un fuerte aporte del erario público (financiamiento estatal), por lo que producir los resultados de la investigación sin publicarlos no tendría razón de ser. Se hace entonces indispensable hacer patente esta asociación integrando ambos aspectos, sobre todo frente a las casas editoriales, de manera que se les pueda poner límites y que rindan cuentas en caso de querer participar en la plataforma de información.

La biblioteca también puede considerar dentro de sus planteamientos el hecho de que el sistema de licencias es sumamente complejo de operar, amén de las dificultades de aplicación según los diferentes contextos legislativos de cada Estado, con lo que sería más eficaz crear un sistema amplio de operaciones de derechos en línea, lo cual facilitaría, entre otras cosas, la educación a distancia. Pero si la misión de la biblioteca es difundir conocimiento y conservar patrimonio cultural, también lo es la investigación y la enseñanza, tareas a las que ella se podría consagrar si no tuviera que drenar gran parte de sus recursos en el pago de cánones por licencias, dado que los precios de suscripción son considerables, y llevar a cabo sus cometidos adecuadamente.

\section{Propuestas y soluciones ${ }^{16}$}

En estas circunstancias, podrían sugerirse ciertas aproximaciones para crear un clima de confianza e instalar una práctica extendida de difusión en libre acceso del saber científico y tecnológico, no solo en el nivel de bibliotecas, sino también por parte de la universidad y de los entes que financian la investigación, por no mencionar más de tres. Las propuestas aquí formuladas se hacen eco de algunas de las soluciones aportadas por el movimiento del libre acceso, a saber:

Para las bibliotecas

- Lanzar un acceso abierto compatible con las iniciativas del Open Access para textos y datos. Se trata de crear repositorios para mejorar la visibilidad e impacto de la investigación, mejorando así también la imagen de la institución.

- Ayudar a los profesores e investigadores a depositar sus artículos 
de investigación en los archivos institucionales, ya que muchos, por estar muy cargados de trabajo, tienen "fobia tecnológica".

- Considerar la posibilidad de publicar una revista de acceso abierto ${ }^{17}$, y de rechazar "jugosos negocios", o cancelar publicaciones cuyos elevados precios no se justifiquen, emanando una declaración donde se explique el porqué de tal medida. Se trata así de promover las bondades del acceso abierto como una solución integral al problema del acceso al conocimiento y denunciar abusos.

- Llevar a cabo los proyectos de digitalización, acceso y preservación no solo en beneficio de los profesores, sino también de los grupos locales sin fines de lucro, organismos comunitarios, museos, galerías y bibliotecas, y sobre todo la comunidad no académica que rodea la universidad.

Para la universidad y la administración

- Adoptar políticas relativas a la contratación, la promoción y la tenencia de información científica: la universidad reconocerá objetivamente el peso y la envergadura de las publicaciones de sus pares, indistintamente del medio y del precio con que se publiquen. Para ello es importante que se deje de penalizar el uso de información en libre acceso y de impedir las publicaciones hechas por este medio, así como basarse en criterios de prestigio y de impacto que van en detrimento de las informaciones, las cuales, aunque sean de calidad, no han tenido ni los medios ni el tiempo de ser debidamente reco- nocidas. Esto iría en contra de la buena comunicación académica.

- En caso de que los profesores publiquen artículos, estos tienen la alternativa de conservar los derechos de autor y de otorgar los de la primera impresión y publicación electrónica, o ceder los derechos de autor y conservar los derechos de archivo después de la publicación.

- Cuando los profesores no tengan los medios para pagar los costos de procesamiento en una revista de acceso libre a pesar de su beca o ayuda para la investigación, la universidad podría asumir estos costos.

- Alentar, e incluso exigir, a sus académicos a depositar en sus archivos los artículos de investigación.

- Toda tesis o memoria de investigación, cuando medie consentimiento, debe quedar abiertamente disponible por medio de un repositorio institucional o en alguno de los archivos interinstitucionales de acceso abierto para este tipo de producciones.

- Todas las conferencias organizadas dentro de la universidad proveerán acceso abierto a sus presentaciones y actuaciones, incluso si la institución opta por publicar las comunicaciones en una revista o libro con precio.

- Todas las revistas alojadas o publicadas en el seno de la universidad deben estar en libre acceso o ser más amigables con este.

- Colaborar con los profesores que investigan y escriben para revistas de libre acceso, proveyéndolos de medios y herramientas para llevar a cabo su labor, como más tiempo para investigar, soporte técnico, ayuda secretarial, publicidad, etc. 
Para financiadores de la investigación

- En cuanto a las becas de investigación, se puede poner la condición de que para ofrecerlas hay que poner en acceso libre los resultados. Para ello se pueden prever ciertas excepciones como asuntos militares, descubrimientos patentables, etc.

- Si el beneficiario de una beca de investigación publica sus resultados en una revista o archivo de libro abierto que exige un monto de dinero para ingresarlos, el ente financiado puede cubrir esos gastos.

- Subvencionar nuevas revistas de acceso abierto así como a sus comités editoriales.

- Dar subvenciones a las revistas para que, en caso de que los autores no puedan costear los procesos de acceso, ellas puedan asumirlo.

- Dar subvenciones a las revistas convencionales para su conversión a revistas de acceso abierto.

Estas propuestas no son exhaustivas. Más bien son una serie de recomendaciones que tienden a configurar un nuevo esquema de funcionamiento en el marco de las sociedades de la información adaptadas a los diferentes contextos bibliotecológicos del mundo. Sin embargo, los principios sobre los que se funda son bastante coherentes y universales, y constituyen una verdadera filosofía de la difusión del conocimiento dirigida a tener impacto directo en la sociedad y el desarrollo del conocimiento.

\section{Conclusión}

Los modelos económicos mundiales están así confrontados a nuevos desa- fíos donde la tradicional economía de mercado está siendo cuestionada en sus fundamentos mismos dado que el libre acceso a la información supone también la gratuidad, palabra clave para comprender el devenir de las relaciones humanas en todo nivel y en particular en lo relativo al hecho de compartir conocimiento, convirtiéndose así en un nuevo paradigma social. Hoy, ya es una realidad el hecho de que los recursos tecnológicos, y en particular la red Internet, permiten hacer circular de manera gratuita cantidad de información que, sin embargo, está enfrentada a la gran dificultad, no de hacerse accesible, sino de ser relevante en términos de calidad. Si la información en libre acceso desea adquirir ese estatus y tener peso en las decisiones e investigaciones científicas serias capaces de transformar la sociedad, en ese caso la exigencia de calidad debe ser fundamental. Ciertamente, el poder reside en la información y el conocimiento, a condición de que ambos hayan sido adquiridos con método y rigor.

También es una realidad que actualmente existe una cultura en línea donde se practica el intercambio de materiales, la extracción de datos y el aprendizaje interactivo, lo cual pone de manifiesto la divergencia de opiniones entre un sistema más permisivo de derechos de autor y un sistema vigente contemplado ya por ley, como la serie de limitaciones y excepciones previstas en los distintos instrumentos legales nacionales y transnacionales. Sin embargo, un conflicto de intereses evidente surge entre los detentores de los derechos de autor y afines a los derechos de autor, y los que abogan por un libre acceso a las fuentes de información con miras a una mejora en la calidad de 
vida de la sociedad en general gracias al acceso libre al conocimiento. Pareciera que el desafío actual, a pesar de los grandes avances en materia de legislación y jurisprudencia vinculante, reside en establecer un justo compromiso y equilibrio entre las dos posiciones de manera que se puedan conciliar los intereses de ambas partes, aunque la tendencia podría ir acentuándose más hacia la sociedad de la información de libre acceso. No se trata solo de tener libre acceso a la lectura, sino también de producir conocimiento a partir de ella y por el mayor número de personas.

El papel de la biblioteca es, en este contexto, fundamental. Ella está llamada a posicionarse con claridad en el panorama para la consecución de los fines y la misión que explican su razón de ser: el interés público, el usuario, la conservación y divulgación del conocimiento. El caso de la Universidad Técnica de Darmstadt es relevador de una verdadera perspectiva epistemológica y ontológica, de su rol e impacto social, posicionada dentro de una visión global, no solo en el presente sino en relación con el futuro. Sus estrategias han tenido eco en las grandes instancias judiciales, son asistidas por la razón jurídica y científica, y tendrán necesariamente repercusiones en el marco nacional, transnacional y mundial. Este ejemplo ha abierto el camino y la perspectiva, y su victoria debe servir de ejemplo para estimular y motivar en la biblioteca iniciativas tendentes a mostrar, frente a la sociedad, el rol fundamental que juega en la difusión del conocimiento para el desarrollo y provecho de este.

\section{Notas}

1 Ver a este respecto la resolución C-117/13 de la Corte de Justicia de la Unión Europea, en el comunicado de prensa $n^{\circ}$ 124/13, publicado en Luxemburgo, el 11 de septiembre de 2014.

2 Ver a título indicativo las obras de: Ricardo Antequera Parilli, Estudios de Derechos de autor y derechos afines, Madrid, Fundación Aisge, 2007., Ahmed Latif, Coordinación de los países en desarrollo en el establecimiento de normas internacionales de propiedad intelectual, Suiza, Centro del Sur, 2005., Eduardo Serrano Gómez, La propiedad intelectual y las nuevas tecnologías, Madrid, Civitas, 2000.

3 La Ley de derecho de autor y derechos conexos define así el derecho moral en su art. 13: "un derecho personalísimo, inalienable e irrenunciable y perpetuo, denominado derecho moral", el cual le confiere al autor ciertas facultades (incisos a. hasta d.). También, se considera el derecho moral como intangible, imprescriptible y discrecional. Por su parte, el derecho patrimonial (art. 15 al 20) se rige por actos contractuales a efectos remunerados o no, derechos que sin embargo no son irrestrictos y que están taxativamente previstos. Comprende derechos de reproducción, de representación y de seguimiento. La comunicación de obras al público de manera directa o indirecta también está prevista en los incisos e) y f) del art. 16.

4 La Asamblea Legislativa de Costa Rica aprobó el tratado mediante la ley $n^{\circ} 7968$, el 22 de diciembre de 1999, y es ratificado por la República mediante decreto ejecutivo $n^{\circ} 28473$ de 15 de febrero de 2000 .

5 Este tratado, que entró en vigor el 6 de marzo de 2002, constituye un ajuste al sentido del artículo 20 de la Convención de Berna para la protección de las obras artísticas y literarias (así como es conocida el 
Acta de París de la Convención de Berna para la protección de las obras literarias y artísticas, de 24 de julio de 1971).

6 Ley $n^{\circ} 6683$ sobre el derecho de autor $y$ derechos conexos (así reformado por ley $\mathrm{n}^{\circ}$ 8834 de 3 de mayo de 2010), texto adoptado el 25 de noviembre de 1982. La legislación costarricense es variada y abundante, fundada en tratados internacionales y normativa nacional bajo forma de ley, decreto o reglamento cuya eficacia se ha visto afectada de alguna u otra manera por una serie continua de reformas o derogaciones (cf. Ley n 8039 de Procedimientos de Observancia de los Derechos de Propiedad Intelectual, modificada por ley $\mathrm{n}^{\circ} 8834$, de 3 de mayo de 2010). Ver Sistema costarricense de información jurídica (SCIJ): http:// www.pgrweb.go.cr/scij/Busqueda/Normativa/Normas/nrm_resultado_simple.aspx?p aram1=NER\&param2=1\&param3=FECHA \&param4=DESC\&param5=ley $\% 20 \mathrm{de} \% 20$ derechos\%20de\%20autor

7 La legislación costarricense conexa es considerable y no se limita a las leyes supracitadas. Podrá consultarse todo el aparato jurídico relacionado con el tema en el Sistema Costarricense de Información Jurídica (SCIJ), donde figuran tratados suscritos y ratificados por la República de Costa Rica, leyes y decretos ejecutivos. En términos de jurisprudencia también podrá consultarse la página web del Poder Judicial: http://jurisprudencia.poder-judicial.go.cr/pj/scij/

8 La legislación francesa de protección de derechos de autor y afines a los derechos de autor, así como de divulgación del conocimiento en las sociedades de información es bastante amplia y precisa. Basta ver el Code de la propriété intellectuelle, art. 1, alinéa 1, ley de 20 de junio de 1992. Toda la legislación de la República francesa al respecto puede ser consultada en el sitio web: http://www.legifrance.
gouv.fr/affichCode.do?cidTexte=LEGITE XT000006069414

9 Art. L 122-2 del Código de la propiedad intelectual.

10 Estos tres últimos párrafos son traducidos por el suscrito a partir de la versión original en francés del art. L 122-5 del Código de propiedad intelectual, modificada por Ley $n^{\circ}$ 2006-961, de 1 de agosto de 2006, relativa al derecho de autor y a los derechos conexos en las sociedades de la información (DADVSI). Cabe recalcar que en cuanto al derecho moral, éste comprende el respeto a la integridad de la obra, el derecho de paternidad, el derecho de retiro y de arrepentimiento, y el derecho a la divulgación, es decir de ceder o no la comunicación de la obra al público. En algunos casos este derecho puede ser abusivo, sobre todo cuando se han cedido los derechos patrimoniales a un tercero.

11 Ver Journal Officiel des Communautés européennes, L 167/10, publicado el 22 de junio de 2001. https://www.dgdr.cnrs.fr/ daj/propriete/droits/droits7.htm Esta directiva debe verse en paralelo a la Directiva 2004/48/CE del Parlamento Europeo y del Consejo de 29 de abril de 2004 relativa al respeto de los derechos de propiedad intelectual http://eur-lex.europa.eu/legalcontent/ES/TXT/PDF/?uri=CELEX:32004L $0048 \&$ qid $=1413305337685 \&$ from $=F R$

12 Se trata del caso C-117/13, en la demanda presentada ante el Bundesgerichtshof (Alemania) el 14 de marzo de 2013 por la Universidad Técnica Darmstadt en la causa emprendida por la casa editorial Eugen Ulmer KG. La sentencia fue publicada mediante comunicado de prensa $n^{\circ} 124 / 14$, en Luxemburgo, el 11 de septiembre de 2014, del Tribunal de Justicia de la Unión Europea. Las conclusiones fueron rendidas el 5 de junio de 2014, mientras que la sentencia fue dictada el 11 de septiembre pasado. 
13 El caso es ampliamente cubierto por la prensa especializada. Léase por ejemplo la serie de artículos de la página web $L e-$ galis: http://www.legalis.net/

14 Ver la sentencia de 14 de noviembre de 2013 en el asunto The Authors Guild et al. vs. Google Inc. (05 CIV 8136), y el Libro Verde intitulado Derechos de autor en la economía del conocimiento [COM(2008) 466 final, p. 8]. Como es sabido, Google digitaliza libros desde el 2002, de los cuales aquellos en dominio público están disponibles para ser descargados por los usuarios desde el 2004, mientras que las obras bajo derechos de autor solo son visibles en extractos. En el 2005, la Authors Guild y la Association of American Publishers presentaron sendas demandas contra Google por infracción masiva a los derechos de autor. En 2013, la Corte del distrito de Nueva York le dio finalmente la razón a Google y se reconoció además el derecho de ampliar su biblioteca digital.

15 Es precisamente en la semana del 13 al 26 de octubre de 2014 que se lleva a cabo la serie de charlas, conferencias y foros sobre el libre acceso a la información, en el marco de la séptima Open Access Week, a la que se ha unido infinito número de bibliotecas de todo el mundo. Este evento permite a la comunidad científica conocer los beneficios del libre acceso, compartir conocimiento y experiencias, y promover el libre acceso a la información. Ver en línea: http://www.fosteropenscience.eu/ y http://www.openaccessweek.org/ Ver también la página web de la Open Archives Initiative: http://www.openarchives.org/

16 La serie de propuestas aquí formuladas son sugeridas por los distintos actores en la reflexión del libre acceso a la información, sin que justamente se pueda distinguir o identificar la pertenencia de las ideas expuestas. Hay que destacar que también la PROSIC (Programa Sociedad de la In- formación y el Conocimiento) de la Universidad de Costa Rica ha hecho propuestas interesantes que pueden consultarse en sus reportes anuales. Ver la página web: http://prosic.ucr.ac.cr/

17 Tal es el caso de las siguientes revistas: http://www. philosophersimprint.org/, http://www.insectscience.org/, http://www. bc.edu/libraries/ y http://jodi.tamu.edu/

\section{Bibliografía}

\section{Normativa y legislación}

Asociación de Profesionales en propiedad intelectual de Costa Rica, Compendio de propiedad intelectual: legislación costarricense, $2^{\text {a }}$ edición, San José, 2009.

Code de la propriété intellectuelle de la República francesa, de 20 de junio de 1992. http://www.legifrance. gouv.fr/affichCode.do?cidTexte=LE GITEXT000006069414

Directiva 2004/48/CE del Parlamento Europeo y del Consejo de 29 de abril de 2004 relativa al respeto de los derechos de propiedad intelectual http://eur-lex.europa.eu/legalcontent/ES/TXT/PDF/?uri=CELEX :32004L0048\&qid=1413305337685 \&from $=\mathrm{FR}$

Ley $n^{\circ}$ 2006-961 relativa al derecho de autor y a los derechos conexos en la sociedad de la información (DADVSI) de la República francesa, de 1 de agosto de 2006, http://www.legifrance.gouv.fr/affichCode.do?cidTe xte=LEGITEXT000006069414

Ley $n^{\circ} 6683$ de derecho de autor $y$ derechos conexos de la República de Costa Rica (reformada por Ley $\mathrm{n}^{\circ}$ 8834 de 3 de mayo de 2010), de 25 de noviembre de 1982 . 
Ley $n^{\circ} 8039$ de Procedimientos de Observancia de los Derechos de Propiedad Intelectual, modificada por Ley $\mathrm{n}^{\circ} 8834$ de 3 de mayo de 2010 .

Tratado de la OMPI, aprobado mediante Ley $\mathrm{n}^{\circ} 7968$ de 22 de diciembre de 1999 , ratificado por la República de Costa Rica mediante decreto ejecutivo $\mathrm{n}^{\circ} 28473$ de 15 de febrero de 2000.

\section{Artículos}

Alfaro López, Héctor Guillermo, Propiedad intelectual y universalidad de la lectura ¿conflicto de intereses?, Bibliotecas: boletín de la Escuela de Bibliotecología, documentación e información de la Universidad Nacional, Heredia, vol. 28, $\mathrm{n}^{\circ} 1$, p. 5-28.

Feltrero Oreja, Roberto, Propiedad intelectual y conocimiento público: derechos del investigador y del ciudadano sobre el copyright, Isegoria: revista de filosofía y ciudadanía, Madrid, n²8, p. 143-158.

García Jiménez, Emmanuel, Uso lícito de material protegido por derechos de autor, Revista de la Universidad de Costa Rica, $\mathrm{n}^{\circ}$ 159, Sección de inteligencias, $13 \mathrm{p}$.

Lorenzo-Escolar, Nieves, La ley de propiedad intelectual y su repercusión en la actividad de las bibliotecas, Revista española de documentación científica, vol. $32, \mathrm{n}^{\circ} 4$, p. 34-45.

Quintana Paz, Miguel Ángel, ¿Es éticamente aceptable la propiedad intelectual de los derechos de autor?, Procesos de mercado: revista europea de economía política, Madrid, vol. $5, \mathrm{n}^{\circ} 1$, p. 91-130.
Ríos Ruiz, Wilson Rafael, Propiedad intelectual en el entorno digital: infracción de los derechos de autor en la red, Bibliotecas y tecnologías de la información, Bogotá, vol. 4, $\mathrm{n}^{\circ} 1$, p. 22-33.

\section{Obras de referencia}

Antequera Parilli, Ricardo, Los derechos de autor y los derechos conexos en el marco de la propiedad intelectual: implicaciones culturales y sociales, su importancia económica, San José, Universidad de Costa Rica, 1998. , Estudios de Derechos de autor y derechos afines, Madrid, Fundación Aisge, 2007.

Latif, Abdel Ahmed, Coordinación de los paises en desarrollo en el establecimiento de normas internacionales de propiedad intelectual, Suiza, Centro del Sur, 2005.

Serrano Gómez, Eduardo, La propiedad intelectual y las nuevas tecnologías, Madrid, Civitas, 2000.

Vibes, Federico P., Derechos de propiedad intelectual, derecho de autor, marcas comerciales [...], Buenos Aires, Ad-hoc, 2009. 